\title{
REACTIVITY OF PHENOL AND ANILINE TOWARDS QUINOLINIUM CHLORO CHROMATE: A COMPARATIVE OXIDATION KINETIC STUDY
}

\author{
Dr. S. K. PERIYASAMY* Mr. H. SATHAM HUSSAIN \\ and Mr. R. MANIKANDAN
}

PG\& Research Department of Chemistry, Jamal Mohamed College (Autonomous), Affliated by Bharathidasan University,Tiruchirappalli, 620 020, Tamilnadu, India

E-mail address: nctperiya85@gmail.com

Keywords: Kinetics, Oxidation, Quinolinium Chlorochromate, Phenol, Aniline, Activation Parameters, Acid catalyst.

\begin{abstract}
The kinetics of Oxidation of Phenol and aniline by quinolinium Chlorochromate (QCC) in aqueous acetic acid medium leads to the formation of quinone and azobenzene respectively. The reactions are first order with respect to both Phenol and aniline. The reaction is first order with respect to quinolinium chlorochromate(QCC) and is catalyzed by hydrogen ion. The hydrogen-ion dependence has the form: $k_{\mathrm{obs}}=a+b\left[\mathrm{H}^{+}\right]$. The rate of oxidation decreases with increasing dielectric constant of solvent, indicating the presence of an ion-dipole interaction. The reaction does not induced the polymerization of acrylonitrile. The retardation of the rate by the addition of $\mathrm{Mn}^{2+}$ ions confirms that a two electron transfer process is involved in the reaction. The reaction rates have been determined at different temperatures and the activation parameters have been calculated. From the above observations kinetic results a probable mechanism have been proposed.
\end{abstract}

\section{INTRODUCTION}

Selective oxidation of organic compounds under aqueous conditions is an important transformation in synthetic organic chemistry. For this, a number of different chromium (VI) derivatives have been reported ${ }^{1-4}$. A number of new chromium containing compounds like pyridinium bromochromate ${ }^{5}$, quinolinium chlorochromate ${ }^{6}, 2,2^{\prime}$-bipyridinium chlorochromate ${ }^{7}$, pyridinium fluorochromate ${ }^{8}$, quinolinium fluorochromate ${ }^{9}$, quinolinium bromochromate ${ }^{10}$, quinolinium dichromate ${ }^{11}$, pyridinium fluorochromate ${ }^{12}$, imidazolium fluorochromate ${ }^{13}$ have been used to study the kinetics and mechanism of oxidation of various organic compounds. Quinolinium chlorochromate(QCC) is a mild and selective oxidant. Quinolinium chlorochromate ${ }^{14}$ is a stable reagent originally introduced as an oxidizing agent for alcohol is used in synthetic organic chemistry ${ }^{15-20}$.

The kinetic mechanistic aspects of oxidation reactions by QCC reports are available in the literature ${ }^{21-26}$ The kinetics of oxidation of Phenols by various oxidizing reagents have been well studied $^{27-29} \cdot$ Phenol is so inexpensive that it attracts many small-scale uses. It once was widely used as an antiseptic, especially as carbolic soap. It is a component of industrial paint strippers used in the aviation industry for the removal of epoxy, polyurethane and other chemically resistant coatings. Phenol derivatives are also used in the preparation of cosmetics including sunscreens, hair colorings, and skin lightening preparations.

The kinetics of oxidation of anilines by various oxidizing reagents have been well studied ${ }^{30-32}$ Anilines are the most widespread and principal contaminates of industrial waste waters. Better understanding of the mechanism of oxidation of such compounds to harmless products. 


\section{Structure of Quinolinium chlorochromate:}

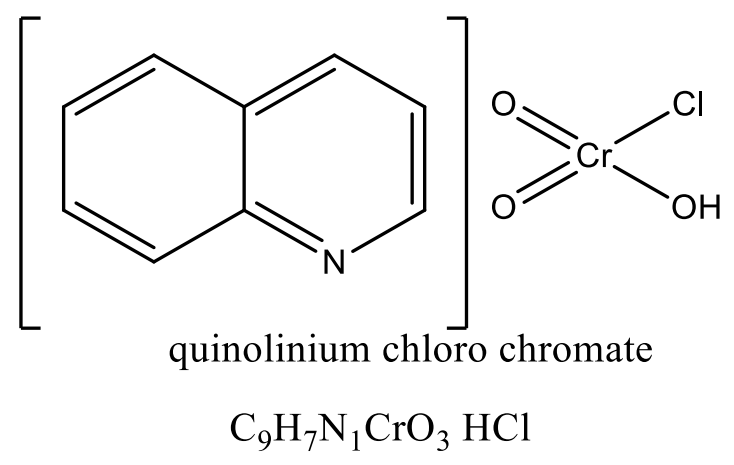

Molecular Weight $=265.61$

Melting Point $=127-130^{\circ} \mathrm{C}$

\section{EXPERIMENTAL}

Materials and methods

All the chemicals used were analytical grade. Phenol and Aniline were used after vacuum distillation. Double distilled water was used for all purposes.

\section{Preparation of Quinolinium Chlorochromate [QCC]}

Chromium trioxide $(7 \mathrm{~g})$ was dissolved in $8 \mathrm{ml}$ of water in a e beaker and $11 \mathrm{ml}$ of $40 \%$ hydrochloric acid were added with stirring at room temperature. A clear orange red solution was formed and $9 \mathrm{ml}$ of quinoline were added drop-wise with stirring. The mixture was heated on a water bath for about $15 \mathrm{~min}$, then cooled to room temperature and allowed to stand for $1 \mathrm{~h}$. The bright yellow crystalline quinolinium chloroochromate was isolated by filtration. It was recrystallized from water and dried in vacuo for about $2 \mathrm{~h}$. The compound melted at $\left(128{ }^{\circ} \mathrm{C}\right)[1$ it m.p $\left.127-130{ }^{\circ} \mathrm{C}\right]^{33}$ and further analysed through spectral studies.

\section{Acetic acid}

The procedure followed for the purification of acetic acid was essentially similar to that of Weissberger ${ }^{34}$ Glacial acetic acid (AR) 2 litre was partially frozen and about one litre of the liquid was removed. The residue was melted and refluxed with chromium trioxide $(30 \mathrm{~g})$ for $4 \mathrm{~h}$ and fractionally distilled. The portion distilling between $116-118^{\circ} \mathrm{C}$ was collected, partially frozen and about half of the acid was discarded as liquid. The remaining residue was melted and fractionated again after treating with chromium trioxide $(30 \mathrm{~g})$. The fraction boiling at $116-118^{\circ} \mathrm{C}$ was collected and kept in brown bottles.

\section{Kinetic measurements}

The kinetic experiments were conducted in aqueous acetic acid $(50 \% \mathrm{~V} / \mathrm{V})$ at $313 \mathrm{~K}$. The reaction mixture consisted of Aniline $=1.00 \times 10^{-2} \mathrm{~mol} \mathrm{dm}^{-3}, \mathrm{QCC}=1.00 \times 10^{-3} \mathrm{~mol} \mathrm{dm}^{-3}$ and $\mathrm{H}_{2} \mathrm{SO}_{4}=1.00 \times 10^{-2} \mathrm{~mol} \mathrm{dm}{ }^{-3}$ and Phenol $=4.50 \times 10^{-2} \mathrm{~mol} \mathrm{dm}^{-3}, \mathrm{QCC}=1.00 \times 10^{-3} \mathrm{~mol} \mathrm{dm}^{-3}$ and $\mathrm{H}_{2} \mathrm{SO}_{4}=3.00 \times 10^{-1} \mathrm{~mol} \mathrm{dm}^{-3}$. The temperature was maintained constant within $\pm 0.2^{\circ}$.

The reactions were carried out under pseudo- first order conditions by maintaining the substrate concentration in excess of quinolinium chlorochromate. Known volumes of substrates, water and acetic acid were mixed to bring the percentage of acetic acid to the desired value and thermostated. The reaction were started by adding the oxidant to the mixture and aliquots were removed at definite time intervals and the decrease in [QCC] by digital photoelectric colorimeter at $470 \mathrm{~nm}$. The reactions were followed up to $70 \%$ completion. The rate constants were obtained from the slope of the plot of log absorbance versus time by the least square method. The results were reproducible within \pm 1 . 


\section{Stoichiometry of QCC and Phenol}

The kinetics of reaction was to establish the stoichiometry of the reaction and identify any side reactions. The stoichiometry of the reaction [QCC]:[Phenol] was determined by taking excess of [QCC] over [Phenol] and allowing the reaction to go for completion. After sufficient length of time, all the substrate has completely reacted to quinolinium chlorochromate leaving behind the unreacted quinolinium chlorochromate. The unreacted quinolinium chlorochromate was estimated iodometrically. The estimation of unreacted quinolinium chlorochromate showed that one mole of substrate consumed by one mole of oxidant. The stoichiometry between phenol and QCC was found to be $1: 1$.

\section{Stoichiometry of QCC and Aniline}

The kinetics of reaction was to establish the stoichiometry of the reaction and identify any side reactions. The stoichiometry of the reaction [QCC]:[aniline] was determined by taking excess of [QCC] over [aniline] and allowing the reaction to go for completion. After sufficient length of time, all the substrate has completely reacted to quinolinium chlorochromate leaving behind the unreacted quinolinium chlorochromate. The unreacted quinolinium chlorochromate was estimated iodometrically. The estimation of unreacted quinolinium chlorochromate showed that one mole of substrate consumed by one mole of oxidant. The stoichiometry between aniline and QCC was found to be $1: 1$.

\section{Product analysis of Phenol}

The reaction mixture containing Phenol $(0.045 \mathrm{M})$ in acetic acid and QCC $(0.001 \mathrm{M})$ in acetic acid was added and the medium was maintained using sulphuric acid. Then the reaction mixture was slightly warmed and was kept aside for about $48 \mathrm{~h}$ for the completion of reaction. After $48 \mathrm{~h}$, the reaction mixture was extracted with ether and dried over anhydrous sodium sulphate. The ethereal layer was washed with water several times and kept on a water bath for ether evaporation and cooled to get the product. Para benzoquinone was identified as product.

The product 1,4 benzoquinone was identified by its physical constant (m.p.113 $\left.{ }^{\circ} \mathrm{C}\right)$ and was confirmed through IR-spectral data and further confirmed by mass spectrum.

\section{Product analysis of Aniline}

The reaction mixture containing Aniline $(0.03 \mathrm{M})$ in acetic acid and QCC $(0.001 \mathrm{M})$ in acetic acid was added and the medium was maintained using sulphuric acid. Then the reaction mixture was slightly warmed and was kept aside for about $48 \mathrm{~h}$ for the completion of reaction. After $48 \mathrm{~h}$, the reaction mixture was extracted with ether and dried over anhydrous sodium sulphate. The ethereal layer was washed with water several times and kept on a water bath for ether evaporation and cooled to get the product. Azobenzene was identified as product.

The product azobenzene was identified by its physical constant (m.p. $68^{\circ} \mathrm{C}$ ) and was detected by comparing with those of the authentic samples.

The product azobenzene was confirmed through IR-spectral data and further confirmed by mass spectrum

\section{RESULTS AND DISCUSSION Effect of varying the Oxidant}

The order with respect to oxidant is one in both the cases of study as evidenced by the linear plot of plot of log absorbance versus time (Fig.1) and also from the constancy of the first order rate constant in (Table 1) 
Table 1: Effect of varying the Oxidant (Quinolinium ChloroChromate)

\begin{tabular}{|c|c|c|c|}
\hline \multicolumn{2}{|c|}{$\begin{array}{c}{[\text { Phenol }]=4.5 \times 10^{-2} \text { moldm }^{-3}} \\
{\left[\mathrm{H}^{+}\right]=3.0 \times 10^{-1} \text { moldm }^{-3}} \\
\text { AcOH-H } \mathrm{H}_{2} \mathrm{O}=50: 50(\%) \\
\text { Temperature }=313 \mathrm{~K}\end{array}$} & \multicolumn{2}{|c|}{$\begin{array}{c}{[\text { Aniline }]=3.0 \times 10^{-2} \text { moldm }^{-3}} \\
{\left[\mathrm{H}^{+}\right]=1.0 \times 10^{-2} \text { moldm }^{-3}} \\
\text { AcOH- } \mathrm{H}_{2} \mathrm{O}=50: 50(\%) \\
\text { Temperature }=313 \mathrm{~K}\end{array}$} \\
\hline$[\mathrm{QCC}] \times 10^{-3} \mathrm{~mol} \mathrm{dm}^{-3}$ & $\mathrm{k}_{1} \times 10^{4} s^{-1}$ & {$[\mathrm{QCC}] \times 10^{-3} \mathrm{~mol} \mathrm{dm}^{-3}$} & $\mathrm{k}_{1} \times 10^{4} s^{-1}$ \\
\hline 0.50 & 16.41 & 0.50 & 3.82 \\
\hline 1.00 & 16.40 & 1.00 & 3.85 \\
\hline 1.50 & 16.42 & 1.50 & 3.83 \\
\hline 2.0 & 16.41 & 2.0 & 3.86 \\
\hline 2.50 & 16.40 & 2.50 & 3.84 \\
\hline 3.00 & 16.44 & 3.00 & 3.81 \\
\hline
\end{tabular}

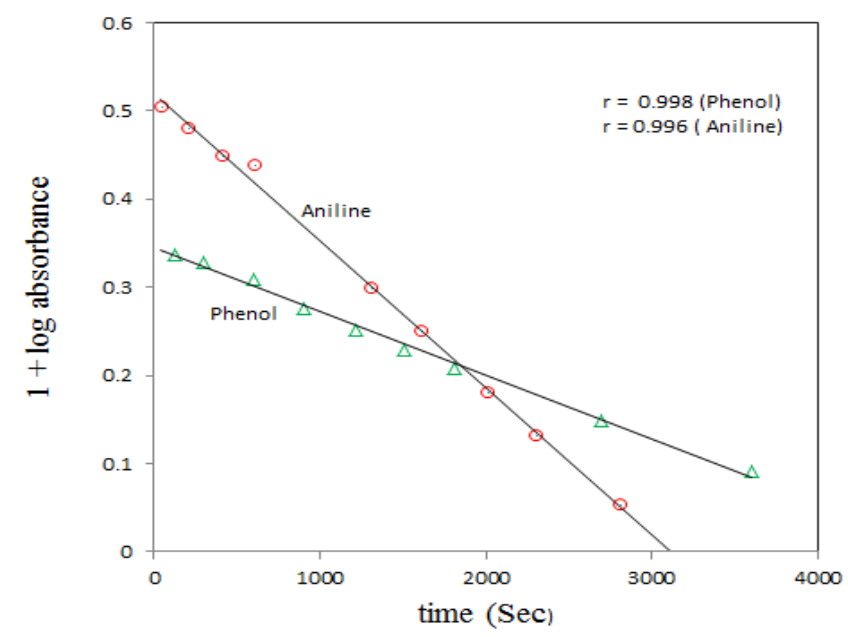

Fig.1: Effect of varying the Oxidant

\section{EFFECT OF VARYING THE SUBSTRATE ( PHENOL AND ANILINE)}

The reactions were carried out by varying the concentration of phenol and aniline keeping the other variables constant. The rate of the reactions increased with increase in the concentration of phenol and aniline. The plot of $\log \mathrm{k}_{1}$ versus $\log$ [Substrate] gave a straight line with a slope of unity (Fig. 2) showing a first order dependence on the substrate. (Table 2 ).

Table 2: Effect of varying the Substrate (Phenol and Aniline)

\begin{tabular}{|c|c|c|c|}
\hline \multicolumn{2}{|c|}{$\begin{array}{c}{[\mathrm{QCC}]=1.00 \times 10^{-3} \text { moldm }^{-3}} \\
{\left[\mathrm{H}^{+}\right]=3.0 \times 10^{-1} \text { moldm }^{-3}} \\
\text { AcOH- } \mathrm{H}_{2} \mathrm{O}=50: 50(\%) \\
\text { Temperature }=313 \mathrm{~K}\end{array}$} & \multicolumn{2}{|c|}{$\begin{array}{c}{[\mathrm{QCC}]=1.00 \times 10^{-3} \text { moldm }^{-3}} \\
{\left[\mathrm{H}^{+}\right]=1.0 \times 10^{-2} \text { moldm }^{-3}} \\
\text { AcOH- } \mathrm{H}_{2} \mathrm{O}=50: 50(\%) \\
\text { Temperature }=313 \mathrm{~K}\end{array}$} \\
\hline$[$ Phenol $] \times 10^{2} \mathrm{~mol} \mathrm{dm}^{-3}$ & $\mathrm{k}_{1} \times 10^{4} s^{-1}$ & [Aniline] $\times 10^{2} \mathrm{~mol} \mathrm{dm}^{-3}$ & $\mathrm{k}_{1} \times 10^{4} s^{-1}$ \\
\hline 3.00 & 12.00 & 1.50 & 1.72 \\
\hline 4.50 & 16.40 & 3.00 & 3.85 \\
\hline 6.00 & 22.38 & 4.50 & 5.75 \\
\hline 7.50 & 27.54 & 6.00 & 7.58 \\
\hline 9.00 & 33.11 & 7.50 & 10.95 \\
\hline 10.50 & 36.30 & 9.0 & 15.83 \\
\hline
\end{tabular}




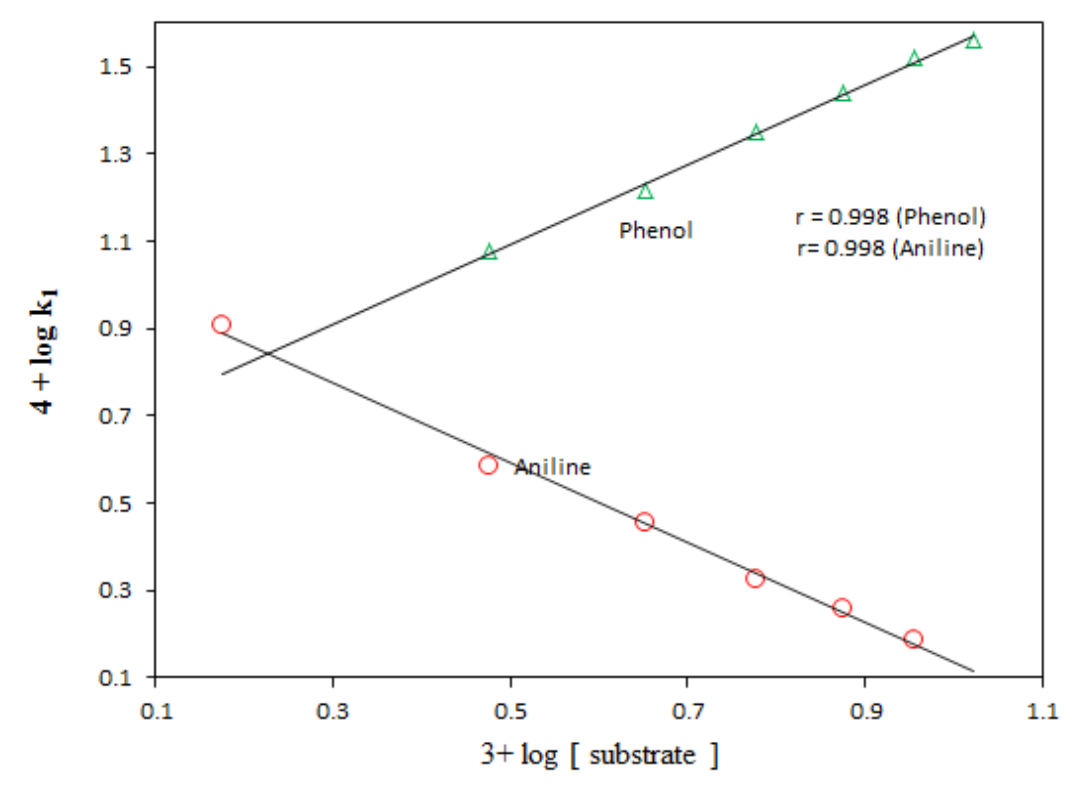

Fig.2: Effect of varying the Substrate (Phenol and Aniline)

\section{EFFECT OF VARYING THE IONIC STRENGTH}

The reactions were studied with varying concentration of sodium sulphate and keeping the other variables constant. The results indicate that ionic strength has negligible effect on the reaction rate, which confirmed the participation of an ion and neutral molecule in the rate determining step ${ }^{35}$ (Table -3)

Table 3: Effect of varying the ionic strength

\begin{tabular}{|c|c|c|c|}
\hline \multicolumn{2}{|c|}{$\begin{array}{c}{[\mathrm{QCC}]=1.00 \times 10^{-3} \text { moldm }^{-3}} \\
{[\mathrm{Phenol}]=4.5 \times 10^{-2} \text { moldm }^{-3}} \\
{\left[\mathrm{H}^{+}\right]=3.0 \times 10^{-1} \text { moldm }^{-3}} \\
\text { AcOH }-\mathrm{H}_{2} \mathrm{O}=50: 50(\%) \\
\text { Temperature }=313 \mathrm{~K}\end{array}$} & \multicolumn{2}{|c|}{$\begin{array}{c}{[\mathrm{QCC}]=1.00 \times 10^{-3} \text { moldm }^{-3}} \\
{[\text { Aniline }]=3.0 \times 10^{-2} \text { moldm }^{-3}} \\
{\left[\mathrm{H}^{+}\right]=1.0 \times 10^{-2} \text { moldm }^{-3}} \\
\text { AcOH }-\mathrm{H}_{2} \mathrm{O}=50: 50(\%) \\
\text { Temperature }=313 \mathrm{~K}\end{array}$} \\
\hline$\left[\mathrm{Na}_{2} \mathrm{SO}_{4}\right] \times 10^{4} \mathrm{~mol} \mathrm{dm}^{-3}$ & $\mathrm{k}_{1} \times 10^{4} s^{-1}$ & {$\left[\mathrm{Na}_{2} \mathrm{SO}_{4}\right] \times 10^{4} \mathrm{~mol} \mathrm{dm}^{-3}$} & $\mathrm{k}_{1} \times 10^{4} s^{-1}$ \\
\hline 0.00 & 16.40 & 0.00 & 3.85 \\
\hline 0.50 & 16.42 & 0.50 & 3.86 \\
\hline 1.00 & 16.41 & 1.00 & 3.85 \\
\hline 1.50 & 16.43 & 1.50 & 3.89 \\
\hline 2.00 & 16.44 & 2.00 & 3.86 \\
\hline 2.50 & 16.46 & 2.50 & 3.87 \\
\hline
\end{tabular}

Effect of varying the hydrogen ion concentration

The reactions followed with different concentration of hydrogen ion keeping the concentration of quinolinium chlorochromate and substrate constant. The rate has been found to increase with increase in concentration of $\mathrm{H}^{+}$. A plot of $\log \mathrm{k}_{1}$ versus $\log \left[\mathrm{H}^{+}\right]$give a straight line (Fig. 3). Since the plot of $\log \mathrm{k}_{1}$ versus $\log \left[\mathrm{H}^{+}\right]$did not give an ideal slope of unity. It is not possible to take the order with respect to $\left[\mathrm{H}^{+}\right]$as one and it can be concluded that the reaction is simply an acid catalyzed one ${ }^{36}$. (Table 4$)$. 
Table 4: Effect of varying the hydrogen ion concentration

\begin{tabular}{|c|c|c|c|}
\hline \multicolumn{2}{|c|}{$\begin{array}{c}{[\mathrm{QCC}]=1.00 \times 10^{-3} \text { moldm }^{-3}} \\
{[\mathrm{Phenol}]=4.5 \times 10^{-2} \text { moldm }^{-3}} \\
\text { AcOH}-\mathrm{H}_{2} \mathrm{O}=50: 50(\%) \\
\text { Temperature }=313 \mathrm{~K}\end{array}$} & \multicolumn{2}{|c|}{$\begin{array}{c}\mathrm{QCC}]=1.00 \times 10^{-3} \mathrm{moldm}^{-3} \\
{[\text { Aniline }]=3.0 \times 10^{-2} \mathrm{moldm}^{-3}} \\
\text { AcOH- } \mathrm{H}_{2} \mathrm{O}=50: 50(\%) \\
\text { Temperature }=313 \mathrm{~K}\end{array}$} \\
\hline$\left[\mathrm{H}^{+}\right] \times 10^{1} \mathrm{~mol} \mathrm{dm}^{-3}$ & $\mathrm{k}_{1} \times 10^{4} s^{-1}$ & {$\left[\mathrm{H}^{+}\right] \times 10^{2} \mathrm{~mol} \mathrm{dm}^{-3}$} & $\mathrm{k}_{1} \times 10^{4} \mathrm{~s}^{-1}$ \\
\hline 1.5 & 5.01 & 0.5 & 1.47 \\
\hline 3.00 & 16.40 & 1.00 & 3.85 \\
\hline 4.50 & 25.70 & 1.50 & 5.88 \\
\hline 6.00 & 36.30 & 2.00 & 9.12 \\
\hline 7.50 & 43.65 & 2.50 & 15.84 \\
\hline 9.00 & 53.70 & 3.00 & 19.95 \\
\hline
\end{tabular}

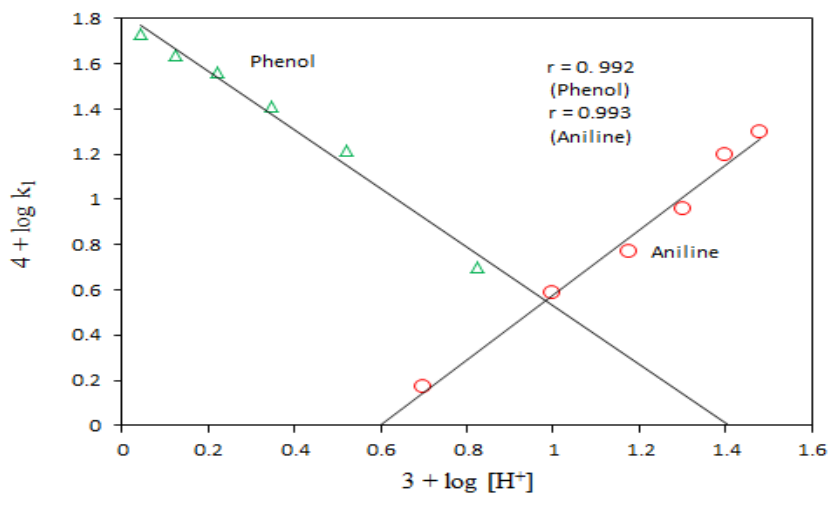

Fig. 3: Effect of varying the hydrogen ion concentration

\section{Effect of varying the solvent composition}

Both the reaction rate were measured at different acetic acid -water mixtures. These reactions are observed that an increase in the percentage of acetic acid considerably increased in the rate of the reaction. The plot of $\log \mathrm{k}_{1}$ versus $\mathrm{D}^{-1}$ gave a straight line with a positive slope (Fig. 4) suggests the involvement of an ion-dipole interaction in the rate determining step ${ }^{37-39}$ (Table 5).

Table 5: Effect of varying the solvent composition

\begin{tabular}{|c|c|c|c|c|c|}
\hline \multicolumn{3}{|c|}{$\begin{array}{c}{[\mathrm{QCC}]=1.00 \times 10^{-3} \text { moldm }^{-3}} \\
{[\mathrm{Phenol}]=4.5 \times 10^{-2} \text { moldm }^{-3}} \\
{\left[\mathrm{H}^{+}\right]=3.0 \times 10^{-1} \text { moldm }^{-3}} \\
\text { Temperature }=313 \mathrm{~K}\end{array}$} & \multicolumn{3}{|c|}{$\begin{array}{c}{[\mathrm{QCC}]=1.00 \times 10^{-3} \mathrm{moldm}^{-3}} \\
{[\text { Aniline }]=3.0 \times 10^{-2} \text { moldm }^{-3}} \\
{\left[\mathrm{H}^{+}\right]=1.0 \times 10^{-2} \text { moldm }^{-3}} \\
\text { Temperature }=313 \mathrm{~K}\end{array}$} \\
\hline $\begin{array}{c}\mathrm{AcOH}-\mathrm{H}_{2} \mathrm{O} \\
\%(\mathrm{v} / \mathrm{v})\end{array}$ & E & $\mathrm{k}_{1} 10^{4} s^{-1}$ & $\begin{array}{c}\mathrm{AcOH}-\mathrm{H}_{2} \mathrm{O} \\
\%(\mathrm{v} / \mathrm{v})\end{array}$ & E & $\mathrm{k}_{1} 10^{4} s^{-1}$ \\
\hline $40-60$ & 50.46 & 15.48 & $30-70$ & 57.85 & 2.81 \\
\hline $50-50$ & 43.08 & 16.40 & $40-60$ & 50.46 & 3.09 \\
\hline $60-40$ & 35.69 & 21.87 & $50-50$ & 43.08 & 3.85 \\
\hline $70-30$ & 28.31 & 23.44 & $60-40$ & 35.69 & 5.62 \\
\hline $80-20$ & 20.92 & 38.01 & $70-30$ & 28.31 & 8.12 \\
\hline $90-10$ & 13.53 & 74.13 & $80-20$ & 20.92 & 19.49 \\
\hline
\end{tabular}




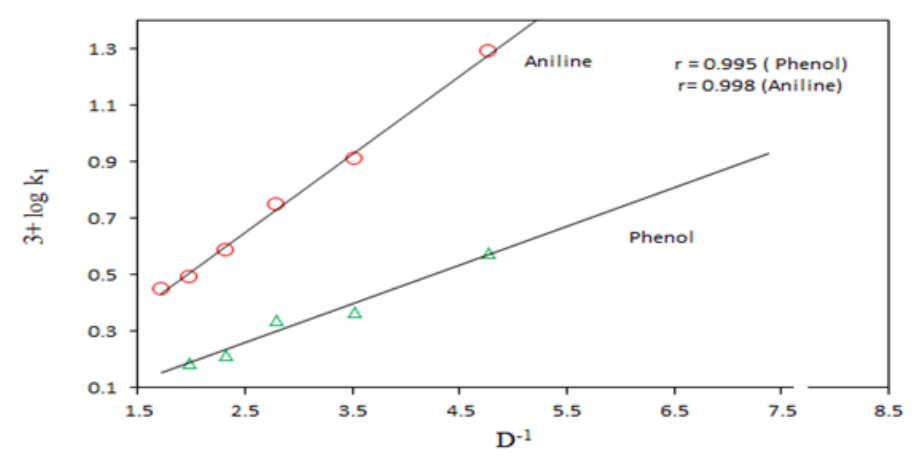

Fig. 4: Effect of varying the solvent composition

\section{Effect of added acrylonitrile}

The added acrylonitrile has no effect on the reaction mixture indicating the absence of free radical mechanism ,no turbidity was obtained.

\section{Effect of varying the manganous sulphate}

These reactions carried out with the varying concentrations of $\mathrm{Mn}^{2+}$ ions keeping all the other factors constant The added $\mathrm{Mn}^{2+}$ ions has decreased the rate of the reaction. It indicates that two electron process may be involved in the reaction ${ }^{40-42}$ (Table 6 ).

Table 6: Effect of varying the manganous sulphate

\begin{tabular}{|c|c|c|c|}
\hline \multicolumn{2}{|c|}{$\begin{array}{c}{[\mathrm{QCC}]=1.00 \times 10^{-3} \text { moldm }^{-3}} \\
{[\mathrm{Phenol}]=4.5 \times 10^{-2} \text { moldm }^{-3}} \\
{\left[\mathrm{H}^{+}\right]=3.0 \times 10^{-1} \text { moldm }^{-3}} \\
\text { AcOH}-\mathrm{H}_{2} \mathrm{O}=50: 50(\%) \\
\text { Temperature }=313 \mathrm{~K}\end{array}$} & \multicolumn{2}{|c|}{$\begin{array}{c}{[\mathrm{QCC}]=1.00 \times 10^{-3} \text { moldm }^{-3}} \\
{[\text { Aniline }]=3.0 \times 10^{-2} \text { moldm }^{-3}} \\
{\left[\mathrm{H}^{+}\right]=1.0 \times 10^{-2} \text { moldm }^{-3}} \\
\mathrm{AcOH}-\mathrm{H}_{2} \mathrm{O}=50: 50(\%) \\
\text { Temperature }=313 \mathrm{~K}\end{array}$} \\
\hline$\left[\mathrm{MnSO}_{4}\right] \times 10^{4} \mathrm{~mol} \mathrm{dm}^{-3}$ & $\mathrm{k}_{1} \times 10^{4} s^{-1}$ & {$\left[\mathrm{MnSO}_{4}\right] \times 10^{4} \mathrm{~mol} \mathrm{dm}^{-3}$} & $\mathrm{k}_{1} \times 10^{4} s^{-1}$ \\
\hline 0.00 & 16.40 & 0.00 & 3.85 \\
\hline 0.50 & 16.38 & 0.50 & 3.83 \\
\hline 1.00 & 16.35 & 1.00 & 3.80 \\
\hline 1.50 & 16.31 & 1.50 & 3.78 \\
\hline 2.00 & 16.25 & 2.00 & 3.76 \\
\hline 2.50 & 16.19 & 2.50 & 3.75 \\
\hline
\end{tabular}

\section{EFFECT OF VARYING THE TEMPERATURE}

Both reactions has been studied at four different temperatures keeping all other factors constant (Table 7).

Table 7: Effect of varying the temperature

\begin{tabular}{|c|c|c|c|}
\hline \multicolumn{2}{|c|}{$\begin{array}{c}{[\mathrm{QCC}]=1.00 \times 10^{-3} \text { moldm }^{-3}} \\
{[\mathrm{Phenol}]=4.5 \times 10^{-2} \text { moldm }^{-3}} \\
{\left[\mathrm{H}^{+}\right]=3.0 \times 10^{-1} \text { moldm }^{-3}} \\
\mathrm{AcOH}-\mathrm{H}_{2} \mathrm{O}=50: 50(\%)\end{array}$} & \multicolumn{2}{|c|}{$\begin{array}{c}{[\mathrm{QCC}]=1.00 \times 10^{-3} \mathrm{moldm}^{-3}} \\
{[\text { Aniline }]=3.0 \times 10^{-2} \text { moldm }^{-3}} \\
{\left[\mathrm{H}^{+}\right]=1.0 \times 10^{-2} \text { moldm }^{-3}} \\
\text { AcOH- } \mathrm{H}_{2} \mathrm{O}=50: 50(\%)\end{array}$} \\
\hline Temperature $\mathrm{K}$ & $\mathrm{k}_{1} 10^{4} s^{-1}$ & Temperature $\mathrm{K}$ & $\mathrm{k}_{1} 10^{4} s^{-1}$ \\
\hline 303 & 13.53 & 303 & 2.76 \\
\hline 308 & 14.85 & 308 & 3.42 \\
\hline 313 & 16.40 & 313 & 3.85 \\
\hline 318 & 17.55 & 318 & 4.32 \\
\hline 323 & 19.65 & 323 & 4.83 \\
\hline 328 & 21.90 & 328 & 5.43 \\
\hline
\end{tabular}




\section{Thermodynamic parameters of Phenol and aniline:}

The thermodynamic parameters have been calculated from the least square procedure of a linear plot of $\ln \left(\mathrm{k}_{2} / \mathrm{T}\right.$ ) versus $1 / \mathrm{T}$ (Fig. 5 ) using Eyring's equation ${ }^{.43,44}$ Phenol thermodynamic parameters are

$$
\begin{aligned}
& \Delta \mathrm{H}^{\#}=12.89 \mathrm{kJmol}^{-1} \\
& \Delta \mathrm{S}^{\#}=-166.81 \mathrm{JK}-1 \mathrm{~mol}^{-1} \\
& \Delta \mathrm{G}^{\#}=65.01 \mathrm{kJmol}^{-1} \\
& \mathrm{Ea}=15.49 \mathrm{kJmol}^{-1}
\end{aligned}
$$

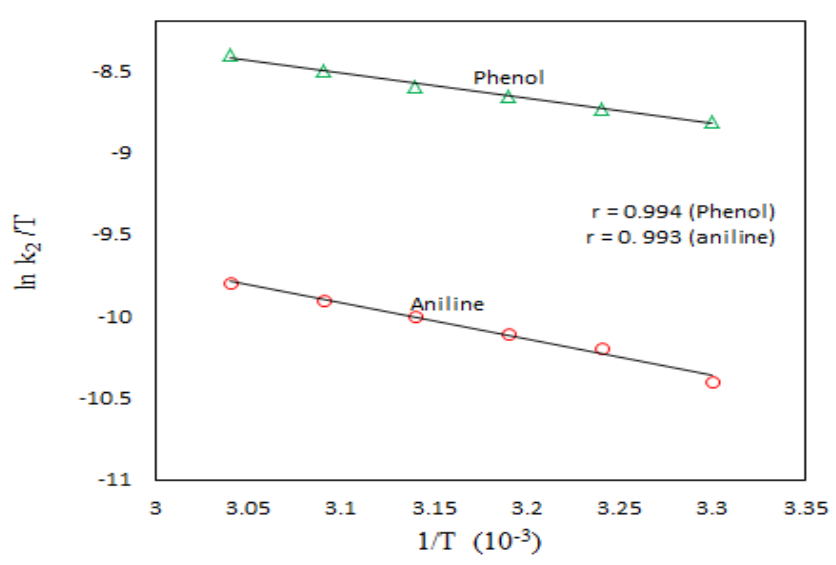

Fig. 5: Effect of varying the temperature

Aniline thermodynamic parameters are

$$
\begin{aligned}
& \Delta \mathrm{H}^{\#}=18.57 \mathrm{kJmol}^{-1} \\
& \Delta \mathrm{S}^{\#}=-172.72 \mathrm{JK}^{-1} \mathrm{~mol}^{-1} \\
& \Delta \mathrm{G}^{\#}=72.62 \mathrm{kJmol}^{-1} \\
& \mathrm{Ea}=21.17 \mathrm{kJmol}^{-1}
\end{aligned}
$$

\section{Mechanism of QCC Oxidation of Phenol}

From the above observation it is clear that the reaction is showing first order with respect to QCC and Phenol. The oxidation by $\mathrm{Cr}(\mathrm{VI})$ will vary with the nature of the $\mathrm{Cr}(\mathrm{VI})$ species used and the solvent will play an important role on the rate of the reaction. In aqueous solution and in the absence of other ions the following are existing, 45

(i) $\mathrm{H}_{2} \mathrm{CrO}_{4} \rightleftharpoons \mathrm{H}^{+}+\mathrm{HCrO}_{4}^{-} \mathrm{K}_{1}=1.21 \mathrm{~mol} \mathrm{dm}{ }^{-3}$

(ii) $\mathrm{HCrO}_{4}^{-} \rightleftharpoons \mathrm{H}^{+}+\mathrm{CrO}_{4}^{2-} \mathrm{K}_{2}=3.0 \times 10^{-2} \mathrm{~mol} \mathrm{dm}^{-3}$

(iii) $2 \mathrm{HCrO}_{4}^{-} \rightleftharpoons \mathrm{Cr}_{2} \mathrm{O}_{7}^{2-}+\mathrm{H}_{2} \mathrm{O} \quad \mathrm{K}_{\mathrm{d}}=35.5$

Here the dimerisation equilibrium is of considerable importance. In water the dichromate ion will be predominating species only at the concentrations greater than about $0.05 \mathrm{~mol} \mathrm{dm}$. In this case as the concentration of $\mathrm{Cr}(\mathrm{VI})$ is less than $0.05 \mathrm{~mol} \mathrm{dm}^{-3}$. The monomeric form predominates and the active oxidising species is $\mathrm{HCrO}_{4}^{-}$. The reaction is acid catalysed one. The rate increased with decrease in the dielectric constant of the medium and increase in ionic strength has negligible effect on the rate. The reaction did not induce polymerization of acrylonitrile indicating the absence of free radical path way. The retardation of the rate by addition of $\mathrm{Mn}^{2+}$ ions confirmed that a two electron transfer process is involved in the reaction. Based on the above facts the following mechanism was proposed (Scheme 1). 


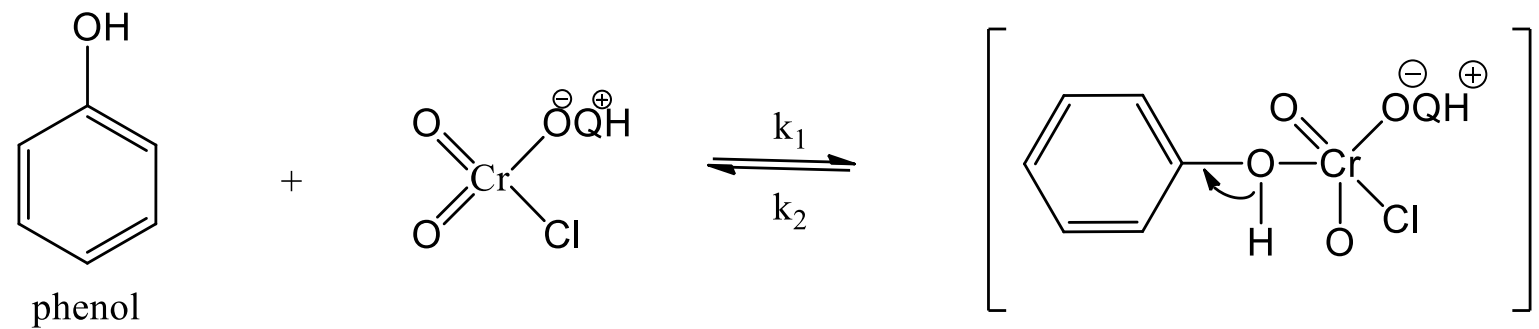

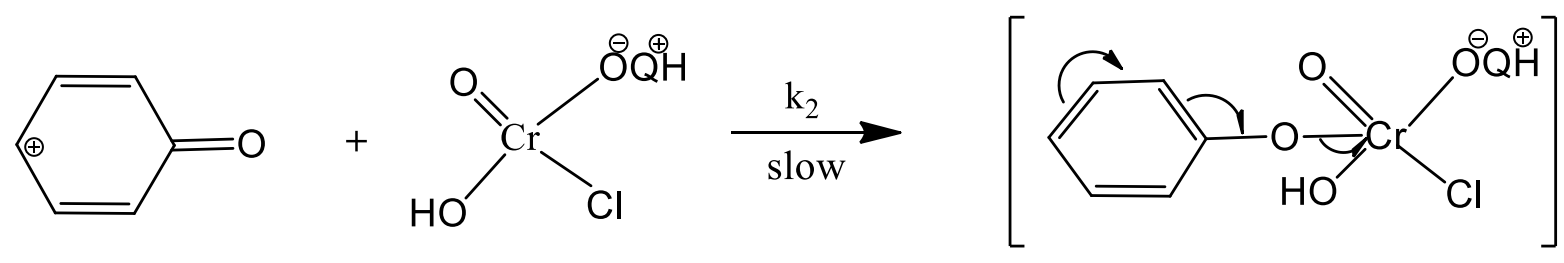

\section{COMPLEX}<smiles></smiles><smiles>O[Ge](O)(O)O</smiles><smiles>O=C1C=CC(=O)C=C1</smiles>

P-Benzoquinone

Scheme1: Probable mechanism of oxidation of Phenol by Quinolinium chlorochromate.

\section{Rate law:}

The above mechanism leads to the following rate law.

\section{Rate $=\mathbf{k}_{\mathbf{1}} \mathbf{k}_{\mathbf{2}} \mathbf{k}_{\mathbf{3}}$ [Phenol] [QCC] $\left[\mathbf{H}^{+}\right]$}

\section{Mechanism of QCC oxidation of aniline}

From the above observation it is clear that the reaction is showing first order with respect to QCC and aniline. The reaction is acid catalysed one. The rate increased with decrease in the dielectric constant of the medium and increase in ionic strength has negligible effect on the rate. The reaction did not induce polymerization of acrylonitrile indicating the absence of free radical path way. The retardation of the rate by addition of $\mathrm{Mn}^{2+}$ ions confirmed that a two electron transfer process is involved in the reaction. Based on the above facts the following mechanism was proposed (Scheme 2). 


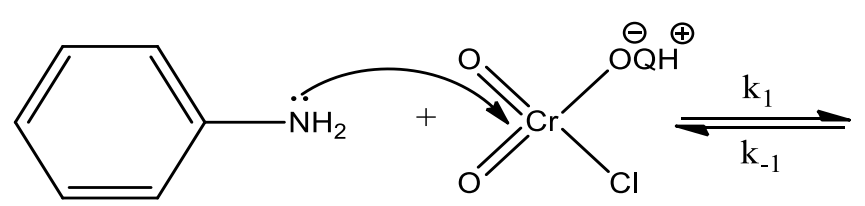

ANILINE

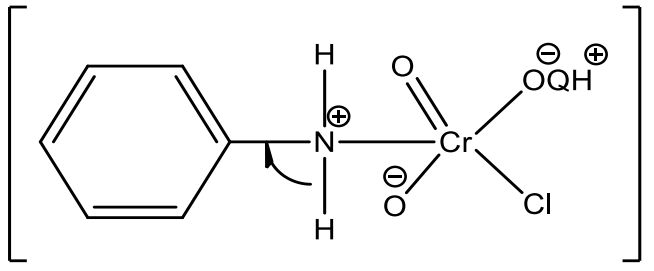

COMPLEX
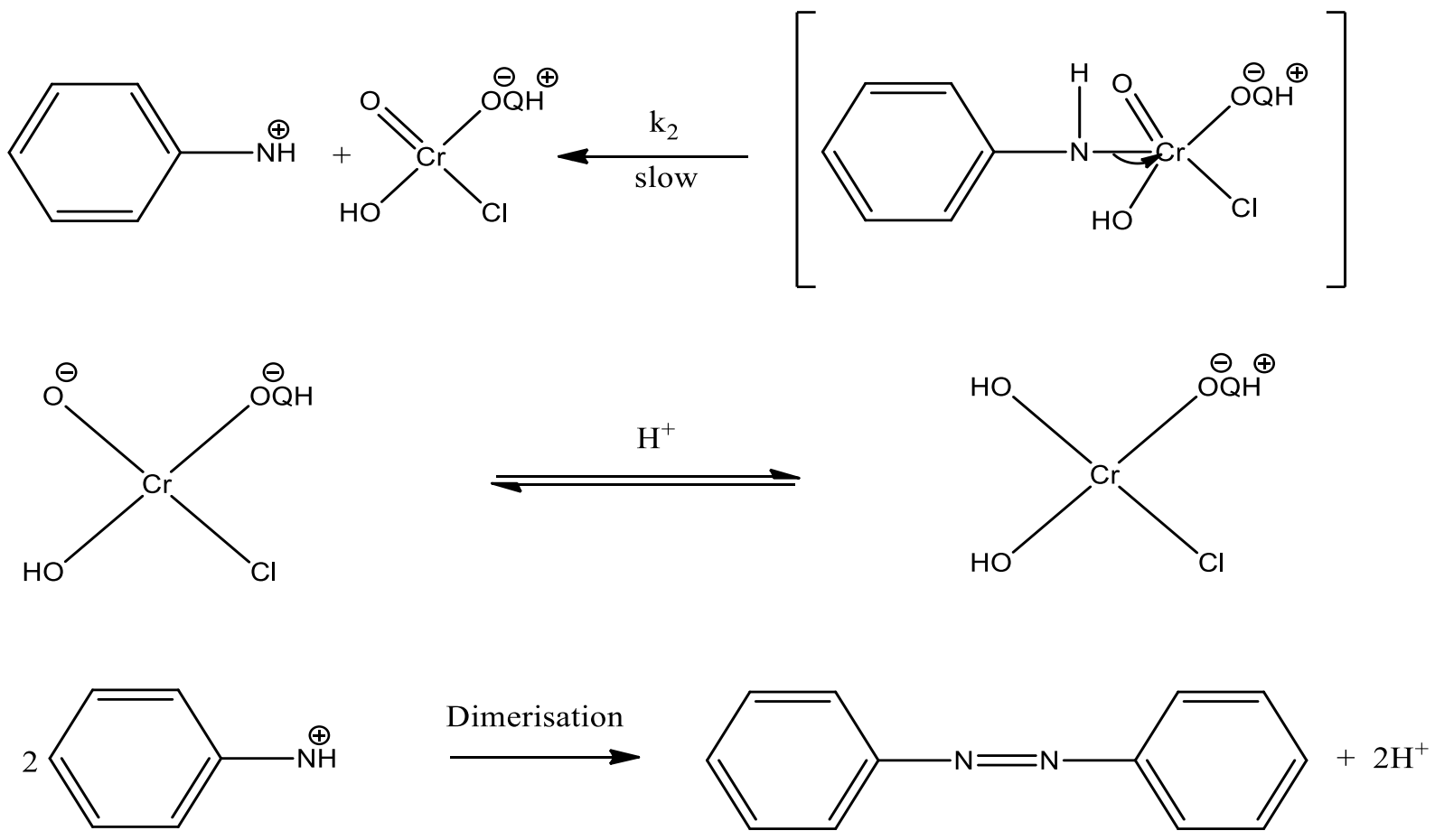

Azobenzene

\section{Scheme: Probable mechanism of oxidation of Aniline by Quinolinium chlorochromate}

\section{Rate law:}

The above mechanism leads to the following rate law.

Rate $=\mathbf{k}_{\mathbf{1}} \mathbf{k}_{\mathbf{2}} \mathbf{k}_{\mathbf{3}}$ [Aniline] [QCC] [ $\mathbf{H}^{+}$]

\section{Conclusion}

In this paper we have reported the detail mechanisms of the aniline and phenol by Quinolinium chlorochromate. The reaction is first order with recpect to oxidant, phenol and aniline. The reaction is acid catalysed by hydrogen ion concentration. The oxidation of phenol yield by para benzoquinone. The oxidation of aniline yield by azobenzene. Since aniline is very harmful to the environment, its removal from the environment is the ultimate coal of basic research. For this purpose deep understanding of the mechanism of the process of phenol and aniline are needed. The negative value of $\Delta \mathrm{S}^{\#}$ provided support for the formation of the activated complex in the slow step. Both of these reactions same rate law obtained. 


\section{Acknowledgement}

The authors thank the Principal and Management, Jamal Mohamed College (Autonomous), Tiruchirappalli, Tamilnadu, India for providing necessary facilities and encouragement.

\section{References}

[1] Corey E J and Suggs W J Tetrahedron Lett. 2647 (1975).

[2] Bhattacharya M M, Chaudhuri M K, Dasgupta H S, Roy N and Kathing D T Synthesis. 588 (1982).

[3] Li M and Johnson M E Synth. Commun. 25 533(1995)

[4] Firouzabadi H and Sharifi A Synthesis. 999(1992).

[5] Dhariwal.V, Yuajurvedi. D and Sharma. P. K, J. Chem. Res. (S) 194(1997).

[6] Gurumurty. R, Gopalkrishnan. M and Karthikeyan. B, Asian J. Chem. 10, 476 (1998)..

[7] Kumbhat. V, Sharma. P.K and Banerji. K. K, Indian J. Chem. 39A, 1169 (2000)..

[8] Patil. S. G, Joshi. S. B, Asian J. Chem. 14, 130, (2002).

[9] Dave. J, Sharma. V and Banerji. K. K, J. Indian Chem. Soc. 79, 347, (2002).

[10] Nalawaya.N, Jain.A and Hiran. B.L, J. Indian Chem. Soc. 79, 587,(2002).

[11] Chimatadar.S. A, Salunke. M. S and Nandibewoor. S. T, Indian J. Chem. 45A,388,(2006).

[12] Kavita. S, Pandurangan. A and Alphonse. I, Indian J. Chem. 44A, 715(2005).

[13] Bhuvaneshwari. D. S and Elengo. K.P, Int. Chem. Kint. 37, 166, (2005).

[14] Khansole. S. V, Patwari. S. B, Vibhute. A. Y and Vibhute. Y. B, Chin. Chem. Lett., 20, 256, (2009).

[15] Srinivasan. R, Ramesh. C. V, Hadhulatha. W and Balasubramanian. K Ind. J. Chem., 35(A), 480, (1996).

[16] Cainelli. G and Cardillo. G, "Chromium Oxidation in Organic Chemistry", Springer Verlag, NewYork, (1984).

[17] Corey. E. J, and Suggs. J. W, Tetrahedron Lett.,16, 2647, (1975)

[18] Murugesan. V and Pandurangan. A, Ind. J. Chem., 31, 377, (1992).

[19] Lonkar. S. M, Mokle. S. S, Vibhute. A. Y, and Vibhute. Y. B., Der Chemica Sinica., 1(2),119(2010).

[20] Vaijayanthi. S. P, Mathiyalagan. N, Der Chemica Sinica., 2(3), 41, (2011).

[21] Pandeeswaran. M, Johns. B, Bhuvaneswari. D. S and Elango. K. P, J. Serb. Chem Soc., 70, 145 (2005).

[22] Saravanakanna.S, Elango. K. P, Int, H, Chem. Kinet., 34, 585 (2002).

[23] Ozgun. B and Degirmenbasi, Monatsh. Chem., 135, 483 (2004).

[24] Singh. J. V, Mishra, K and Pandey. A, Oxid. Commun., 26, 235 (2003).

[25] Singh.J. V, Mishra. K and Pandey. A, Bull. Polish Acad. Sci., 51, 25 (2003).

[26] Chaubey. G. S, Kharsyntiew. B and Mahanti. M. K, J. Phys. Org. Chem. Commun., 17, 83 (2003).

[27] Rajalakshmi. K and Ramachandramoorthy.T Int.J. Res. Pharm\&bio science., 03, 1050 (2012). 
[28] S.Khnasole.S.V and Patwari.S. B Int. J. Res. Phy. Chem ., 03, 01 (2013).

[29] Usama Akram Saeed, J. Eng. Development., 18, 1813 (2014).

[30] Exner.O, Streitwiser. R. W and Taft. R. W, "Progress in physical organic chemistry", John wiley, New York, 41(1973).

[31] Eyring.H, J.Chem. Phys., 33, 107 (1935).

[32] Rajalakshmi.K, Ramachandramoorthy.T and Srinivasan,S, Rasayan J. Chem., 5(1) 28(2012).

[33] Kumar rai,K, Kannaujia,R, Karuna Rai and Surjeet Singh, Orien. J. Chem.,29, 1071 (2013).

[34] Weissberger, A and Prabhakar. E. S, "Organic solvents Physical Properties and Methods of Purifications", $2^{\text {nd }}$ ed., Interscience Publishers Ltd., London (1963).

[35] Chockalingam.P, Ramakrishnan,P.S, Arulraj. S. J and Nambi,K, J. Indian Chem. Soc., 69, 247 (1992).

[36] Patwari.S. B, Khansole. S. V and Vibhute. Y. B, J. Iran. Chem. Soc.,6, 399(2009).

[37] Rao.C. N, “A Hand Book of Chemistry and Physics" Affiliated East-West Press, New Delhi (1967).

[38] Amis. E. S, "Solvent Effects on Reaction Rates and Mechanism", Academic Press, New York(1967).

[39] Quinlan and Amis. E. S, J. Am. Chem. Soc., 77, 4187 (1955).

[40] Graham. G. T. E and Westheimer. F. H, J. Am. Chem. Soc., 80, 3030 (1958).

[41] Gurumurthy. R and Karunakaran. K, J. Indian Chem. Soc., 72, 349 (1995).

[42] Karthikeyan.G, Elango. K. P, Periyasamy. V and Vijayakumar. K, Asian J. Chem., 7(4), 705 (1995).

[43] Frost. A and Pearson. R. G “Kinetics and Mechanism” Eastern, New Delhi (1970).

[44] Eyring.H, J. Chem. Phys., 33, 107 (1935).

[45] Wiberg. K. B and Mill.T, J. Am. Chem. Soc., 80, 3022 (1958). 